dread of extermination through lack of the simple necessities of life. Freedom from want is therefore the most comprehensive of all the freedoms, and as Sir John Orr has so aptly pointed out, this freedom must be among those first things which will have to come first.

In this fight for establishing freedom from want, science will have to play a very important part. In fact, its aid is now being invoked in the preparations already being made for dealing with the acute problems for which we shall have to be ready immediately hostilities have ended. To do all this efficiently and quickly, science must be properly planned and organized so that it can play its part efficiently and not along those haphazard lines which have so frequently been characteristic of it in the past. This is one of the conceptions which the War has forced upon us. While we must never condemn any piece of scientific work because we cannot attach any immediate utilitarian value to it, at the same time men of science must recognize their duties to society and thus be willing to be properly organized so that they give the maximum of service to the community, to the State and to the world. Sir Stafford Cripps and his newly appointed scientific advisers form an excellent example of what can be done in war-time. Let us hope that the lesson will not be forgotten in the peace to follow. Here we have science organizing itself with the help, but not the coercion, of the State.

\section{ORGANIZATION OF POST-WAR RELIEF IN EUROPE}

$\Delta \mathbf{N}$ admirable report of a Study Group of the $A$ Royal Institute of International Affairs ontitled "Relief and Reconstruction in Europe : the First Steps", outlining and relating to one another some of the immediate practical problems which will confront Europe when the War ends, makes its appearance when leading American statesmen have indicated their firm support of the broad policy laid down by Mr. Winston Churchill in his declaration of August 20,1940, in connexion with the sending of relief to Europe. The report is a preliminary survey of the specific problems, of a general as well as a technical nature, which are involved in that policy. The studies on which the report is based are limited to Britain's policy towards Europe.

Mr. Churchill's declaration was followed by the declarations of the Allied Governments at a meeting at St. James's Palace on September 24, 1941 : that it was their common aim to secure that supplies of food, raw materials and articles of prime necessity should be made available for the post-war needs of the countries liberated from Nazi oppression, and that while each of the Allied Governments and authorities would be primarily responsible for making provision for the economic needs of its own peoples, their respective plans should be co-ordinated for the successful achievement of the common aim. This aim of social security abroad no less than at home has been affirmed repeatedly by Mr. Eden as an objective of British foreign policy, and in his speech at Notting. ham on July 23 he pointed out that the first task would be to feed the starving populations. There was also, he said, the problem of enabling devastated, impoverished and economically undeveloped countries to restart their agriculture and industry. Here two principles should govern the relations between such countries and those more highly developed : receipt of financial and economic aid must not result in any loss of independence for any country ; and any form of assistance or guidance given to a country unpractised in the art of self-government must be such as to help it to achieve its own development.

The recent Washington Conference led to a scheme for ensuring that large supplies of food will be avail. able for distribution when the time comes, and since the establishment of the bureau for collaborating in framing estimates of requirements of foodstuffs, raw materials and articles of prime necessity agreed upon at the Inter-Allied meeting on September 24, 1941, Russia has entered the Allied Councils. Obviously, her representatives will be specially fitted to give guidance on relief problems in eastern Europe. Moreover, the United Nations will also be able to call on the help of such surviving machinery of the League of Nations as the Economic and Financial Sections and of the International Labour Organisation.

Neither relief nor reconstruction, the report points out, can be carried out in a state of anarchy. The most urgent task of all, the transportation and distribution of food, depends on the existence of a minimum of order, and while in some countries the objects of the Allies will be achieved in association with a Government which enjoys their confidence and co-operation, in others their association with what purports to be the governing authority will require careful thought. Moreover, publicity as well as policy will be important and should be the subject of Allied consultations. The execution of measures of relief will require the constant use of publicity to give information and instruction to the people concerned. Allied control of broadcasting and news services and propaganda organs will be necessary in countries under military occupation, or through which Allied lines of communication pass, first as a direct military measure, secondly to prevent propaganda likely to frustrate the execution of Allied policy ; and thirdly, to foster in ex-enemy countries such constructive and co-operative tendencies as exist.

This problem of authority and order is discussed in considerable detail with reference to Germany, where the difficulties are likely to be greatest. The analysis is on lines similar to that of a Planning (PEP) broadsheet issued last year, but stress is laid on the necessity that nothing should be done or permitted which conflicts with the cardinal aim of effectively dissolving German armed power. While the situation in Germany at the end of the War may well be one of chaos, tempered more or less by force of bureaucratic habit, the actual task of control may not be so difficult as it seems. A far-reaching military occupation will undoubtedly be necessary, and apart from disarmament, which must begin at once, the Allies 
must be prepared to accept heavy administrative, military and economic burdens if the opportunity of making Europe secure is not again to be thrown away.

If effective immediate help is to be given, plans for action in the economic, social and technical fields must be drawn up in advance, so that they may be put into operation simultaneously with measures for restoring order and authority. Last-minute improvisation, though in some respects unavoidable, may lead to confusion. Similarly, it is true that, in view of the uncertainty of the future, the plans drawn up must be flexible and will require revision from time to time.

The main task will be to organize food relief and health measures, and the report urges that the only hope of achieving rough justice in the allotment of priorities would be to regard Europe, or those parts of Europe to which we have access, so far as possible as a whole from the beginning. This will demand an important moral and intellectual effort of the more favoured peoples, and particularly cognition by the politically effective groups that a community of interests between the European peoples exists and demands this first instalment of practice. In point of urgency of need, no real distinction will be possible between the supplies required to meet immediate human wants, such as food, clothing and medica. ments, and supplies of seeds, fertilizers and certain kinds of raw materials. An adequate relief policy must provide both; but whatever can be done beforehand to settle the major aims of policy will increase the chance of effective immediate action.

The report recalls, in sufficient detail to enforce this point of the necessity of planning relief in advance, the handling by the Allies of the re-victualling of Germany after the War of 1914-18. While the financial and political conditions on which Germany should receive relief in accordance with the estimate of her needs should be determined beforehand so far as possible, the character of the immediate measures will be determined also by the views which may be formed on the economic future of Europe, and on the institutional framework which it is desirable to establish. It is already widely recognized that both national and international organizations will be required, and the report elaborates the steps by which there might be developed a Reconstruction and Supply Authority, with wide powers and a flexible organization, from the Inter-Allied Bureau and Committee to which reference was made at the Inter-Allied meeting on September 24, 1941. This Authority, working with and through the local authorities, whether national governments or other serviceable elements, should be capable of mobilizing the resources of technical knowledge, co-operative will and administrative capacity wherever they are found. Its activities will of course require co-ordination with those of the Armistice Commission or other interAllied authority responsible for the-re-establishment of order and the disarmament of enemy States.

The experience of 1918 emphasizes the importance of a clear understanding on the vital matter of organization well in advance, and whatever use may be made of existing machinery, its efficacy in action will largely depend on careful planning, the first general object of which is to form, and constantly revise, an estimate of the actual changing situation in Europe and what is needed to meet it; the condition and probable needs of agriculture; the state of transport, both ocean-going and internal; the state of health, particularly with respect to deficiency diseases and the risk of epidemics; refugees, transferred labour and other movements of population; financial position; raw materials and plant necessary to restore peace-time production; administrative personnel likely to be available-all these will require estimates. Much guesswork will obviously be inevitable, but it should be reduced to a minimum.

It is probable that fairly accurate provisional re. quirement programmes could be prepared for most countries by the Bureau, and estimates made of the supplies likely to be available to meet them. Such programmes should be prepared, where practicable, on the basis of regions dependent on particular ports, so that all shipments to the same region may be bulked, thus enabling account to be taken of local supplies and allowing the use of local surpluses for distribution in that region. In estimating requirements, use should be made of recent scientific work on standard diets, and to meet the urgent demand for supplies, large stocks must when possible be held in readiness. A beginning has already been made with the establishment of a Ministerial Committee on Export Surpluses. Flexibility will be essential if the best use is to be made of the available supplies and shipping.

From food and supplies the report turns to the question of health, and against the gloomy picture of widespread epidemics and an increase of disease generally, especially those directly or indirectly connected with malnutrition, it sets the various organizations which will be available to aid the national health services. On this point of organization it is emphasized that, while relief work under the direct control and supervision of the body providing relief is the easier and may be necessary in the initial stages, it is essential to operate as soon as possible only through the Government concerned and by utilizing that Government's machinery. Secondly, the control of starvation and such diseases as may be expected after the War depends primarily on transport, economic reconstruction and agricultural recovery, and only secondarily on medical personnel and drugs. Any medical relief organization should be closely linked from its inception with these three branches of relief work.

The report makes the third point that medical relief work must be regarded as part of the work of a future international body and should become part of this organization as soon as it is created. It is suggested that on the conclusion of hostilities, use should be made of the Health Organisation of the League of Nations which, with greatly reduced personnel, still operates in Geneva. From some points of view this would be a rapid and efficient solution of many of the urgent medical problems that will at once arise. Apart from this question of deciding what type of central co-ordinating organization is to be 
used for urgent medical relief work, the immediate tasks are to encourage among the voluntary organizations action designed to co-ordinate post-war relief measures and to examine the possibility of building up supplies of medical relief stores.

In regard to transport, the importance of relief convoys and personnel being able to move freely across frontiers without being held up unnecessarily by Customs and other formalities is urged. Such measures as a waiving of national road transport licensing systems and the removal of other obstacles to through transport of all kinds are desirable. Much greater co-ordination will be required among air communications, which should gradually pass into civilian hands as soon as possible. In regard to movements of population, disorderly dispersal, whether in camps or in large industrial undertakings, should be prevented by military or other Allied officials on the spot with power to provide for immediate needs and instructions for the workers to remain where they are until proper arrangements for their transfer can be made. Alternatively, instructions should be given in advance, if possible, to trade union or other leaders through their national Governments or their trade union organizations.

The relief and reconstruction problem is a supply problem, and financial considerations in the narrower sense will play only a secondary part. Broadly speaking, those providing the supplies will in the first instance have to take the responsibility. A positive supply policy based on priorities in relation to needs will be required ; even major financial questions should not be allowed to cause delay. The report indicates briefly a number of the measures which will be required, such as limitations on personal expenditure by rationing, canalization of investment and control of the capital market. There will be no orderly procedure by which Europe, having subsisted on outside relief for a brief period of convalescence, will then set itself to reconstruct its peace-time economy. The twa processes will be simultaneous and inextricable, though later, one will absorb the other. In regard to agriculture, the Reconstruction and Supply Authority could probably perform a valuable service by providing technical advice, but to form an adequate estimate of the requirements of industry even for the immediate post-war period will demand a clear view of long-term economic policy. What is important is that the study of these questions should be undertaken at the earliest possible moment. Meanwhile, the evolution of the actual situation in Europe should be closely followed, and as long-term policy becomes more clearly defined, at least provisional opinions should be formed as to which tendencies should be reversed and which maintained, so far as the decision rests in Allied hands.

The urgency of planning for post-war reconstruction is demonstrated quite as conclusively in a further monograph, also issued by the Royal Institute of International Affairs, under the title "Medical Relief in Europe : Questions for Immediate Study", in which Dr. Melville D. Mackenzie gives an excellent though brief outline of some of the medical consequences of war and of the measures which a medical relief organization must be equipped to apply. Starting with a review of the factors, such as movements of populations, agricultural breakdown, transport difficulties and general economic strain on the population, impairment of public health and hospital services, which contribute to post-war medical problems, Dr. Mackenzie draws effectively on the ex. periences of relief work in 1919 and the following years to emphasize the need for a central medical authority covering the whole of Europe and prepared to go into action as soon as hostilitios cease. On this question of organization he reiterates the arguments advanced in the report already quoted, but goes into further detail as to the problems which could be dealt with by a Medical Committee before the end of hostilities. This will include the collection and pooling of reports on medico-social conditions in Europe, the reconstruction of medical services, equipment and stores, the determination of standard rations, and the study of the medical needs of special groups.

Dr. Mackenzie then proceeds to discuss in some detail the special problems which may be expected to arise from malnutrition, typhus fever and malaria, and the preparation which might be made to deal with the situation. There follow admirably argued concise chapters on the necessity for the resumption of international health work in the light of the results achieved during the last twenty years, and on considerations relating to the re-establishment of a permanent international medical organization. These alone are of interest to every scientific worker, and they fully substantiate the conclusion that the urgent medical problems which will require solution the moment hostilities cease can already be discerned so clearly as to make immediate action both possible and essential.

It is true that the form of permanent constructive work in the sphere of international medicine depends so much on political, economic and social develop. ments in the post-war period that any attempt to envisage it on more than the broadest lines is prema. ture. Much, however, can clearly be learned from difficulties encountered, successfully or unsuccessfully, in the past ; and it is equally clear that only through international collaboration can the fullest use be made of our neighbours' and our own knowledge in the control of ill-health throughout the world. Solely by such co-operation can research be co-ordinated to avoid waste of effort, the spread of epidemics checked, and clinical and administrative knowledge pooled for the benefit of all. The nature of the most effective permanent machinery, how and when it can be created, and the exact tasks it should undertake, are questions linked with the future welfare of every community. Even in the present crises, they cannot fail to engage the deep thought of men of vision in every community.

These two publications of the Royal Institute of Intermational Affairs are a sufficient answer to those who would defer consideration of planning for postwar reconstruction, either on the ground that attention must not be diverted from more urgent tasks or that the situation which such plans must meet is still unpredictable. 